\title{
norden
}

Nordic Council of Ministers

Ved Stranden 18

DK-1061 Copenhagen K

www.norden.org

NORDISKE ARBEJDSPAPIRER

NORDIC WORKING PAPERS

\section{How can the Nordic experience be used for nutrition in the future?}

Emphasis on Nordic Regional Nutrition Co-operation

School of Health Sciences, University of Iceland

National Food Institute, Technical University of Denmark

http://dx.doi.org/10.6027/NA2014-921

NA2014:921

ISSN 2311-0562 


\section{Working paper}

How can the Nordic experience be used for nutrition in the future?

Emphasis on Nordic Regional Nutrition Co-operation

November 2014

$$
\text { Prepared by }
$$

School of Health Sciences, University of Iceland National Food Institute, Technical University of Denmark 
UNIVERSITY OF ICELAND

SCHOOL OF HEALTH SCIENCES

\section{Content}

Preface....... 4

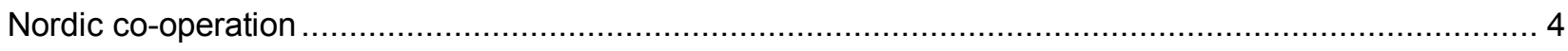

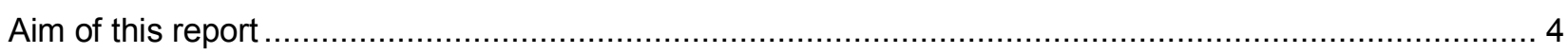

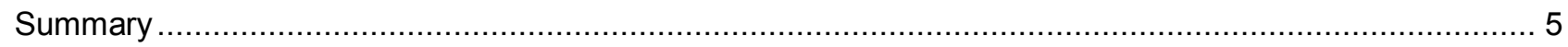

1. Review of progress in selected nutrition status parameters in the Nordic countries ............................. 6

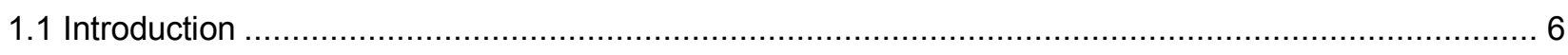

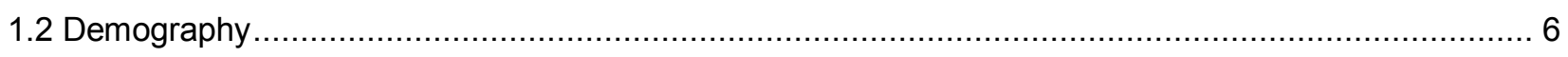

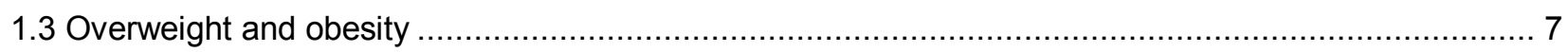

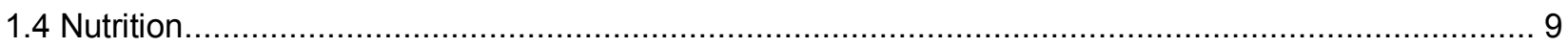

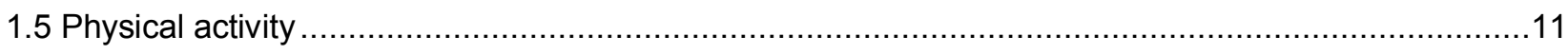

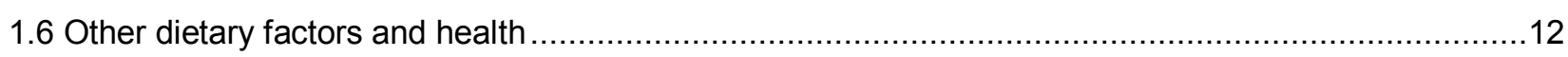

2. Review of progress in nutrition-enhancing policies and programs in the Nordic countries......................14

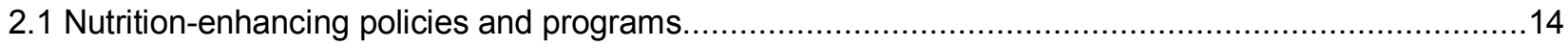

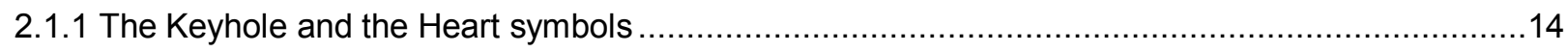

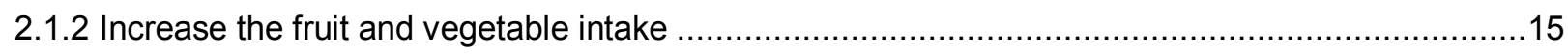

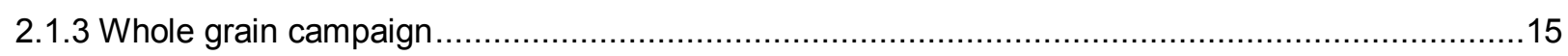

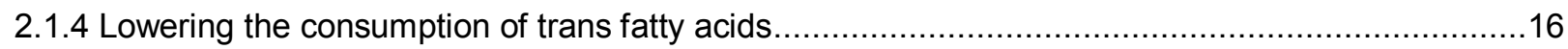

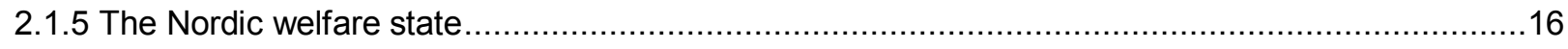

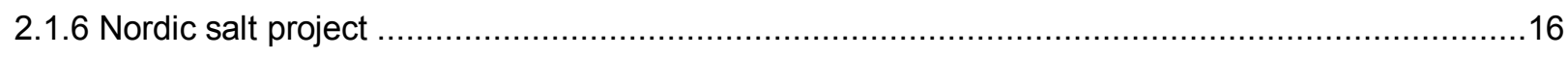

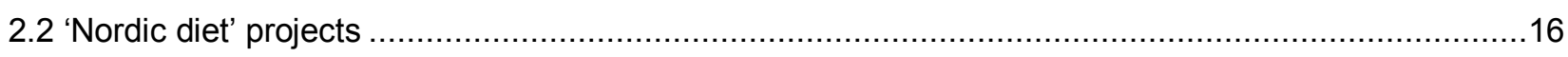

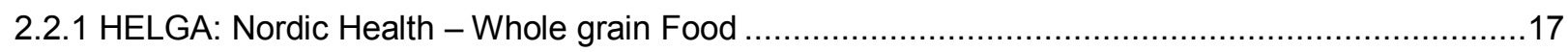

2.2.2 MITOHEALTH: Centre for Bioactive Food Components and Prevention of Lifestyle Diseases ......18

2.2.3 SYSDIET: Systems biology in controlled dietary interventions and cohort studies ......................18

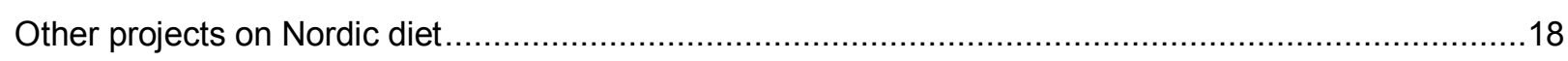

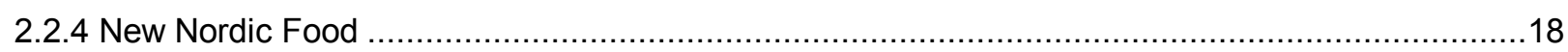

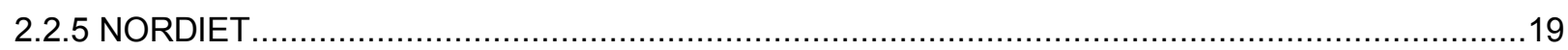

2.2.6 OPUS: Optimal well-being, development and health for Danish children through a healthy New

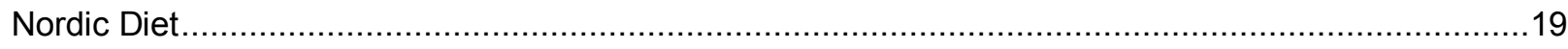

2.3 Risk analysis approach: assessment, management and communication ...................................19

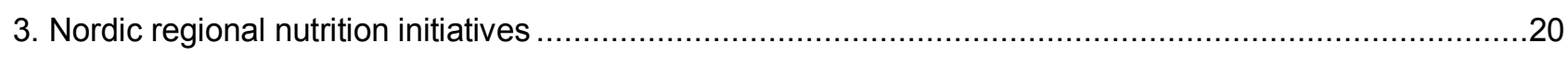

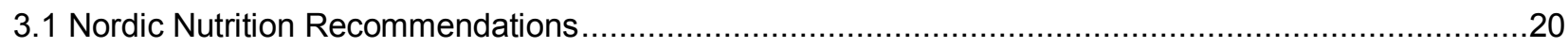

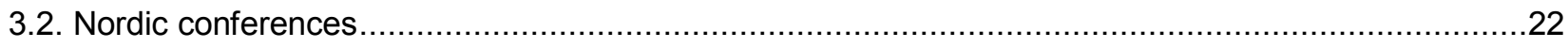

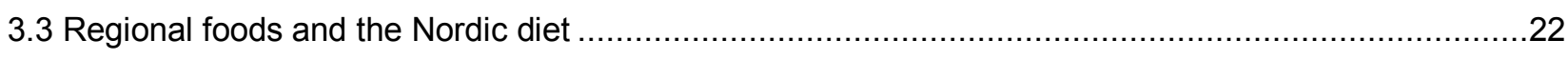

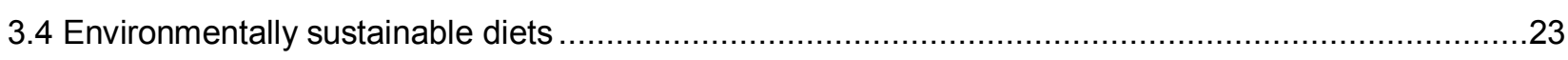




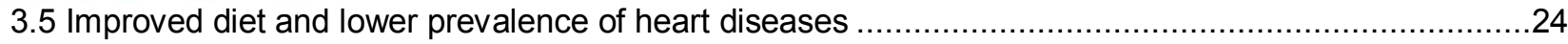

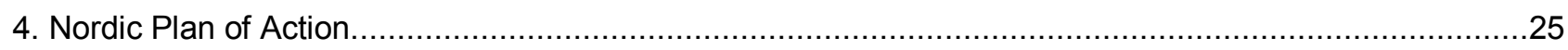

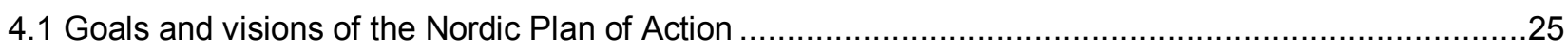

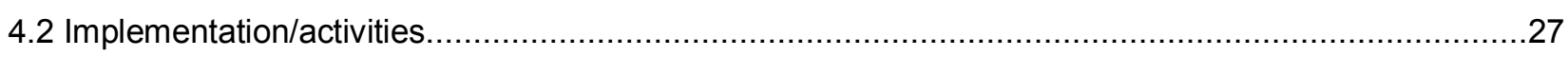

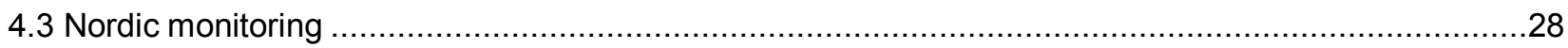

4.3.1. Part 1. Description of common methods for collecting representative data on diet and physical

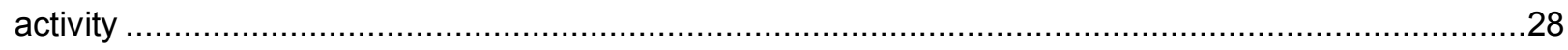

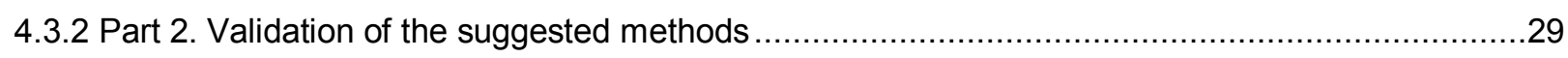

4.3.3 Part 3. First collection of data in all Nordic countries ..............................................................30

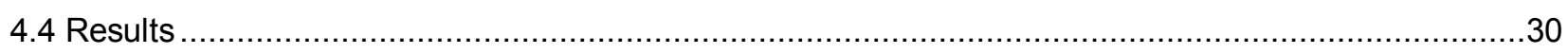

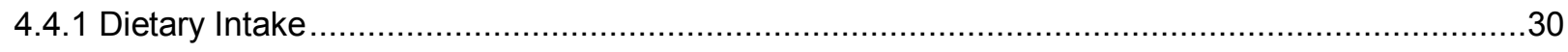

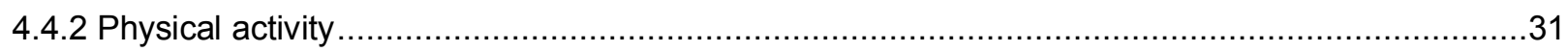

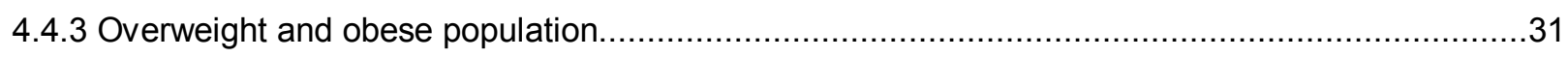

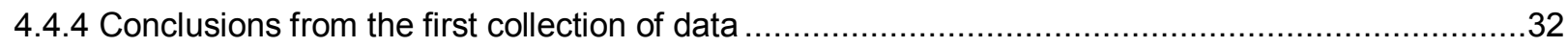

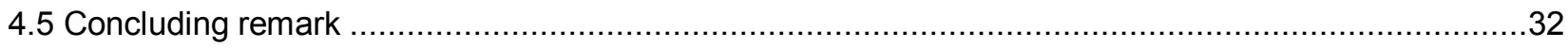

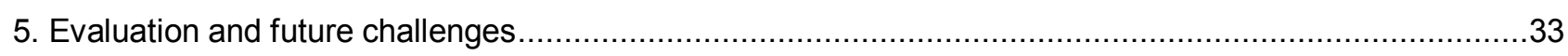

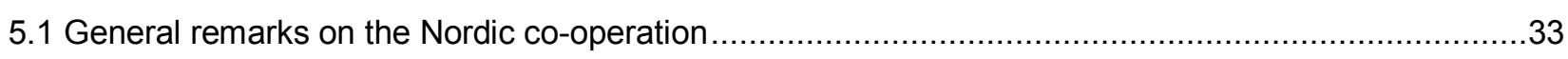

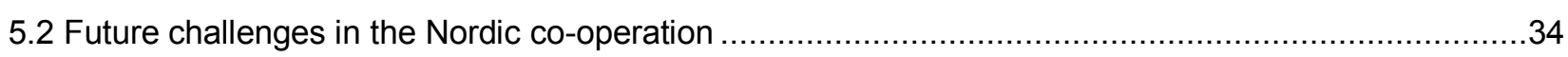

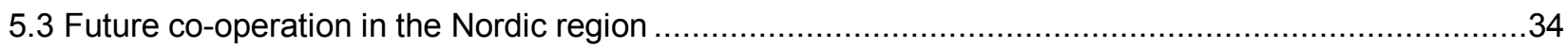




\section{Preface}

\section{Nordic co-operation}

\section{Aim of this report}

The aim of the present report is to describe the common Nordic activities and progress obtained in the Nordic countries through the Nordic co-operation in the area of nutrition for the period from the International Conference on Nutrition (ICN) in 1992 to the ICN 2014. It is also having a view on the Nordic Plan of Action on Better Health and Quality of Life through Diet and Physical Activity established in 2006 and having goals for 2021. 


\section{Summary}

Nordic co-operation has a long history and is built on a set of common values. The effort has resulted in a number of common nutrition-enhancing policies and programs, including the Nordic Plan of Action on better health and quality of life through diet and physical activity (the Nordic Actionplan). The development of the "Keyhole" symbol, which started in Sweden, is now integrated in four of the Nordic countries, and the "Heart" symbol in Finland is another example of successful progress of exchanging experiences between countries in the same region. The Nordic regional nutrition initiatives comprise the development and updating of a common set of Nordic Nutrition Recommendations (NNR) that also serve as a common basis for development of local Food-Based Dietary Guidelines (FBDG) for dietary planning in public institutions and as a basis for product innovation in the food industry. The Nordic countries have collaborated extensively through nutrition research projects investigating the association of a 'Nordic diet' and health. Environmental sustainability is an important criteria in the development of Nordic diets. Having similar tools and approaches with a clear distinction between assessment, management and communication has been fruitful in the Nordic co-operation in the area of food, nutrition and health. A Nordic Plan of Action and a monitoring system have been developed with goals and visions for the future and have been of major importance in the regional attempt to monitor the trends in dietary intake, physical activity, overweight and obesity. The collection of baseline data shows both similarities and also considerable differences between the countries. The Nordic Action Plan has however considerably added to the tool box for improved diet, health and the possibility of measurements to follow the trends. Future monitoring will be able to inform whether the positive trends in the development of nutrition and health during the last decades can be continued and whether the challenges can be overcome through common nutrition-enhancing policies and programs. 


\section{Review of progress in selected nutrition status parameters in the Nordic countries}

\subsection{Introduction}

The purpose of this part of the report is to review the progress made in terms of health status in the five Nordic countries participating in the Nordic Plan of Action on diet and physical activity since 1992. For the past 8 years, Denmark, Finland, Iceland, Norway and Sweden have collaborated on a broad-based approach to health promotion and disease prevention, including research and monitoring of health, based on mutual Nordic values. ${ }^{(1)}$ Valuable information has been shared as a result of these joint efforts in terms of promoting public health in the Nordic countries. This report presents the development and current status in all five countries in the following four areas: demography, overweight and obesity, nutrition and physical activity. The data applied originates primarily from the individual Country Nutrition Papers from Food and Agriculture sectors prepared for ICN+21, ${ }^{(2-5)}$ except for Iceland where local information was gathered especially for the purpose of this report. These data were complimented with statistics from the World Health Organization Regional Office for Europe ${ }^{(6)}$ and the Organisation for Economic Co-operation and Development $(\mathrm{OECD}){ }^{(7)}$ as well as relevant partners.

\subsection{Demography}

All five Nordic countries have increased in population size since 1992 as well as added years to the national life expectancies for both men and women (Table 1). A common reason for the increasing population sizes is the increasing rates of immigration to the Nordic countries, especially Denmark, Norway and Sweden. ${ }^{(2-4)}$ In Sweden, the population number would in fact have decreased had it not been for immigration. ${ }^{(4)}$ In terms of life expectancy, added life years are also documented for most other countries ${ }^{(7)}$ and hence, may be a result of global societal changes and public health improvements. Unlike the other four countries, life expectancy in Denmark has been causing concern because the statistics remain low compared to neighbouring countries. ${ }^{(7)}$ All five Nordic countries seem to identify improved medical treatment in the ageing populations as a contributing factor to the increased life expectancy more so than decreased disease prevalence. With a higher proportion of elderly, the role of medical treatment becomes more significant in relation to prolonging life. 
Table 1. Demographic data.

\begin{tabular}{lcccc}
\hline Countries & \multicolumn{2}{c}{ Total population } & \multicolumn{2}{c}{ National life expectancy (years) } \\
\cline { 2 - 5 } & $\mathbf{1 9 9 2}$ & $\mathbf{2 0 1 1 - 1 2}$ & $\begin{array}{c}\mathbf{1 9 9 2} \\
\text { (Male/Female) }\end{array}$ & $\begin{array}{c}\mathbf{2 0 1 1 - 1 2} \\
\text { (Male/Female) }\end{array}$ \\
\hline Denmark* $^{\text {(Minland* }}$ & 5.162 .000 & 5.561 .000 & $73 / 78$ & $77 / 82$ \\
Iceland† $_{\text {Norway* }}^{5.054 .982}$ & 5.426 .674 & $72 / 79$ & $77 / 84$ \\
Sweden $^{*}$ & $262.193^{\ddagger}$ & $319.575^{\S}$ & $73 / 81^{\ddagger}$ & $80 / 84(2008)$ \\
& 4.300 .000 & 5.038 .100 & $74 / 80$ & $79 / 84$ \\
& 8.692 .013 & 9.482 .855 & $75 / 81$ & $80,3 / 84$
\end{tabular}

*Sources: ICN Country Nutrition reports.

${ }^{\dagger} \mathrm{WHO}$ country profiles on nutrition, physical activity and obesity in the 53 WHO European Region Member States. ${ }^{(8)}$ No nutrition report was available from Iceland.

${ }^{\ddagger}$ Statistics Iceland (www.hagstofa.is). ${ }^{(9)}$

\subsection{Overweight and obesity}

During the last decade, the prevalence of obesity among adults in the Nordic countries has increased (Table 2). Both among adults and children, the proportion of overweight and obese people has been increasing during the last decade (Table 3), which is alarming considering the additional risk of diseases later in adulthood. ${ }^{(6)}$ However, a number of countries report stagnation in the prevalence of overweight subjects from 2010 and onwards among both adults ${ }^{(2,4)}$ and children ${ }^{(2-5,7,10,11)}$, which may indicate some positive trends in the Nordic countries. A possible stagnation in the increasing prevalence of overweight and obese population may well be the result of extensive initiatives implemented to improved school meals and children's nutrition as well as other initiatives related to physical activity. ${ }^{(12)}$ The development is being followed closely. 
Table 2. Prevalence of adult (25-64 y) obesity (BMl>30) in the Nordic countries assessed from self-reported body weight as published in the Nordic Nutrition Recommendations $2004{ }^{(13)}$ and 2012. ${ }^{(14)}$

\begin{tabular}{lcccc}
\hline Countries & \multicolumn{2}{c}{ Women } & \multicolumn{2}{c}{ Men } \\
\cline { 2 - 5 } & $\mathbf{2 0 0 4}$ & $\mathbf{2 0 1 2}$ & $\mathbf{2 0 0 4}$ & $\mathbf{2 0 1 2}$ \\
\hline Denmark & 9.8 & 14.8 & 10.9 & 15.6 \\
Finland & 13.8 & 19.3 & 13.5 & 18.2 \\
Iceland & 13.5 & 19.4 & 13.4 & $22.7^{*}$ \\
Norway & 8.6 & 22.1 & 10.0 & 21.0 \\
Sweden & 10.2 & 14.0 & 12.2 & 13.0
\end{tabular}

*Source: What do Icelanders eat? Research on the Food Habits of Icelanders 2010-2011. (15), Figures for men at 18-80 years of age. Corrected figure from the NNR 2012.

Table 3. Overweight and obesity in children.

\begin{tabular}{ccc}
\hline Countries & \multicolumn{2}{c}{ Overweight and obese children $(\%)^{*}$} \\
\cline { 2 - 3 } $2009-11$ & From 2000 \\
& (Boys/Girls) \\
\hline
\end{tabular}

Denmark

Finland

Iceland

Norway

$19 / 22$

$14 / 10$

Sweden

(only obese)
Increased

13

(only obese)
Not increased"l

Increased

Increased

*Sources: ICN Country Nutrition reports. ${ }^{(2-5)}$

${ }^{\S}$ Figures for children living in the capital city of Iceland, approximately $2 / 3$ of Icelandic children in 2012. Source: Directorate General of Health, Iceland (http://www.landlaeknir.is). ${ }^{(10)}$

$\|$ Comparative figures are countrywide for 6 years olds. Thorisdottir B et al. 2013. ${ }^{(11)}$ 


\subsection{Nutrition}

Exclusively breastfeeding a baby until six months of age has been recommended by WHO with continued breastfeeding until 12 months of age. ${ }^{(16)}$ Breastfeeding rates in the Nordic countries have been increasing in the last decades and are relatively high. The prevalence of exclusive breastfeeding at 4 months has increased in all Nordic countries since 2004, except in Sweden, although there, the frequency of breastfeeding is still high. ${ }^{(14)}$ However, trends seem to suggest that exclusive breastfeeding in the Nordic countries decreases considerably after four months (Table 4). ${ }^{(2,4,7,17-19)}$ Denmark reports the highest percentage of exclusive breastfeeding until six months. ${ }^{(20)}$

Table 4. Reported breastfeeding rates (\% exclusive and any breastfeeding) among children born in the Nordic countries (in Denmark little data is available and only proportion of exclusive breastfeeding at 1 month, 4 months and 6 months is available).

$\begin{array}{lllllllll}1 \mathrm{w} & 1 \mathrm{~m} & 2 \mathrm{~m} & 3 \mathrm{~m} & 4 \mathrm{~m} & 5 \mathrm{~m} & 6 \mathrm{~m} & 9 \mathrm{~m} & 12 \mathrm{~m}\end{array}$

Excl Any Excl Any Excl Any Excl Any Excl Any Excl Any Excl Any Any Any

\begin{tabular}{|c|c|c|c|c|c|c|c|c|c|c|c|c|c|c|c|c|}
\hline Denmark* & & & 68 & & & & & & 57 & & & & 12 & & & \\
\hline Finland $^{\dagger}$ & & & 46 & 87 & 39 & 80 & 34 & 77 & 23 & 68 & 9 & 66 & 0 & 58 & 39 & 34 \\
\hline Iceland $^{\ddagger}$ & 86 & 98 & 87 & 94 & 80 & 91 & 67 & 86 & 63 & 84 & 35 & 79 & 8 & 74 & 45 & 27 \\
\hline Norway ${ }^{\S}$ & & & 82 & 95 & 73 & 91 & 63 & 88 & 46 & 85 & 25 & 82 & 9 & 80 & 63 & 46 \\
\hline Sweden" & 83 & 97 & & & 67 & 87 & & & 51 & 76 & & & 11 & 63 & 34 & 16 \\
\hline
\end{tabular}

${ }^{*}$ Children born in 2012 in Denmark. ${ }^{(20)}$

${ }^{\dagger}$ Children born in 2010 Finland. Health and Welfare report 2012. ${ }^{(21)}$

${ }^{\ddagger}$ Children born in 2005-06 in Iceland. Nationwide randomized cohort ${ }^{(17)}$ and in 2004-2008,

Directorate General of Health, Iceland. ${ }^{(18)}$

${ }^{\S}$ Children born in 2006 in Norway. National dietary surveys. ${ }^{(22,23)}$

$\|_{\text {Children born in }} 2010$ in Sweden. National statistics 2012. ${ }^{(24)}$

Amounts of average daily consumption of both fruits and vegetables in grams per person have increased considerably during the past decade (see Table 5). Norway presents the highest intake of vegetables, ${ }^{(3)}$ where Denmark ${ }^{(2)}$ has the highest intake of fruit. Common trends among the 
Nordic countries show not only increased fruit and vegetable consumption, but also decreased consumption of fat ${ }^{(2)}$ and added sugar, ${ }^{(3)}$ though the common Nordic Nutrition Recommendations (NNR) are still not met. According to the WHO country profiles, all Nordic countries have a mean intake of saturated fatty acids between 12 and 15 per cent of the total calorie intake, exceeding the recommended maximum of 10 per cent of energy intake. ${ }^{(14,19)}$ Intake of trans fatty acids, however, are reported within the recommended restricted level with three of the five countries having formulated bans on trans fatty acids. Denmark was the first country to implement legislation in 2003 followed by Iceland in 2011 and then Norway. In Sweden, the Parliament has recently voted for a declaration on a prohibition against trans fatty acids and is waiting for an opinion report from the EU Commission.

Table 5. Nutrition data for adults in the Nordic countries.

\begin{tabular}{|c|c|c|c|c|c|c|c|c|}
\hline \multirow[t]{2}{*}{ Countries } & \multicolumn{2}{|c|}{$\begin{array}{c}\text { Average daily } \\
\text { vegetable intake } \\
\text { (g/person)* }\end{array}$} & \multicolumn{2}{|c|}{$\begin{array}{l}\text { Average daily fruit } \\
\text { intake (g/person) }{ }^{*}\end{array}$} & \multicolumn{2}{|c|}{$\begin{array}{l}\text { Average daily salt intake } \\
\text { (g/person })^{*}\end{array}$} & \multicolumn{2}{|c|}{ 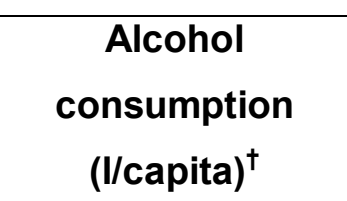 } \\
\hline & 1989-92 & $2010-12$ & 1989-92 & 2010-12 & $\begin{array}{c}\text { 1989-92 } \\
\text { (Male/Female) }\end{array}$ & $\begin{array}{c}2010-12 \\
\text { (Male/Female) }\end{array}$ & 2011 & $\begin{array}{l}\text { \% change } \\
\text { from } 1990\end{array}$ \\
\hline & & 160 & & 282 & & & & \\
\hline \multirow[t]{2}{*}{ Denmark } & 117 & (2008) & 162 & (2008) & - & $9-11 / 7-8$ & 10,6 & -9 \\
\hline & & 134 & & 104 & & & & \\
\hline \multirow[t]{2}{*}{ Finland } & - & (2007) & - & (2007) & $12 / 8$ & $9 / 6,5$ & 9,8 & +3 \\
\hline & $71^{\S}$ & $120^{\|}$ & $67^{\S}$ & $119 \|$ & & & & \\
\hline Iceland $^{\ddagger}$ & (1990) & $(2010-11)$ & (1990) & $(2010-11)$ & Not calc ${ }^{\S}$ & $9,5 / 6,5$ & 7,3 & +40 \\
\hline Norway & 146 & 202 & 213 & 238 & - & $10 / 9$ & 6,6 & +30 \\
\hline Sweden & 87 & 176 & 115 & 128 & - & 7,5 & 7,4 & +16 \\
\hline
\end{tabular}


Recommendations are not met in terms of salt intake with all five countries reporting intakes of 1-6 $\mathrm{g}$ above the recommended, maximum $6 \mathrm{~g} /$ day. However, the salt reduction achievements documented in Finland have been quite significant but very recent data suggest that an upward trend in salt intake is occurring. The experiences and documentation of changes provide a strong basis for further improvement in the future. Because most of the salt intake stems from the consumption of industrialised food products, partnerships with the food industry have been initiated in several countries to reformulate food products with lower salt and sugar content. ${ }^{(2-4)}$ These partnerships along with increased taxations on sugary food and beverage products, and in some cases also on alcohol, ${ }^{(3)}$ seem to have been successful during the last decade and continue to be implemented.

Alcohol consumption in litres per capita is also included in Table 5, based on estimates from OECD. A high level of alcohol consumption is common in all Nordic countries, as compared with other OECD countries, with the Danish population drinking the most. However, Denmark is also the only of the five countries which has experienced a decrease in consumption since 1990, where the other four have increased in consumption. This is especially true for Iceland and Norway. Alcohol consumption is important to consider in terms of nutrition because alcohol contains a high amount of calories, alcoholic beverages contain a low amount of nutrients and alcohol consumption has been found to contribute to several diet-related diseases.

\subsection{Physical activity}

Table 6 shows the proportions of the Nordic populations who are defined as inactive and those who meet both moderate- and vigorous-intensity activity recommendations. This table is based on data for all countries, presented by Rasmussen and co-workers. ${ }^{(26)}$ The Icelandic population is the most inactive compared with the four other Nordic countries, while Finland includes the highest proportion of the population meeting the full recommendation. In Norway, a trend of decreasing activity with increasing age in children has been identified. ${ }^{(3)}$ On average for the populations in all five countries, 67 per cent met the minimum recommendation and 13 per cent of these met the full recommendation. ${ }^{(26)}$ The Nordic Plan of Action includes measures to improve the general level of physical activity in all Nordic countries by 2020 . 
Table 6. Physical activity in adults 2011.

\begin{tabular}{lccccc}
\hline $\begin{array}{l}\text { Physical activity } \\
\text { levels* }\end{array}$ & Denmark & Finland & Iceland & Norway & Sweden \\
\hline Physically inactive $^{\dagger}$ & 33.4 & 29.6 & 35.0 & 38.8 & 30.8 \\
\hline $\begin{array}{l}\text { Meeting minimum } \\
\text { recommendations }\end{array}$ & 55.0 & 53.1 & 53.7 & 51.0 & 56.0 \\
$\begin{array}{l}\text { Meeting the full } \\
\text { recommendations }\end{array}$ & 11.6 & 17.3 & 11.3 & 10.2 & 13.2
\end{tabular}

*Source: Rasmussen LB et al. 2012. ${ }^{(26)}$

${ }^{\dagger}$ Proportion of population not meeting the minimum recommendation of physical activity .

\# Proportion of the population meeting the minimum recommendation of moderate- and/or vigorous-intensity physical activity

₹ Proportion of the population meeting both the moderate-intensity activity recommendation (1.25 hours per week) as well as the vigorous-intensity recommendation ( 3.5 hours per week).

\subsection{Other dietary factors and health}

In addition to the tables presented above, the following public health developments have been emphasised in terms of health status in the Nordic countries.

None of the five Nordic countries report significant problems with micronutrient deficiencies and therefore, no data are available on deficiency related to undernourishment in any of the countries. lodine fortification of salt has been applied widely since 2000 to increase intake and avoid insufficient intakes. Low vitamin D status is common in all five countries due to the Nordic latitude and limited sunlight during the winter months. Therefore, the use of vitamin $D$ supplements is widely encouraged for the elderly and for immigrants, and for all the population during wintertime in two of the Nordic countries, along with guidelines for iron and folate supplements for the more vulnerable population groups such as pregnant women. In terms of food and water safety, none of the Nordic countries report serious issues.

Contrary to nutrient deficiencies, diet-related diseases such as cardiovascular disease (CVD), type 2 diabetes and cancer represent considerable health challenges in all five Nordic countries.

Generally, the prevalence of type 2 diabetes and some types of cancer has increased during the last decades in the Nordic countries, but mortality rates have decreased according to reports from Denmark, Finland, Norway and Sweden, mainly due to improved medical treatment. ${ }^{(2-4)}$ It has been suggested by the OECD that a reduction in tobacco use has contributed to the remarkable 
decline in mortality rates related to ischaemic heart disease experienced in Denmark and Norway since the 1990s. ${ }^{(7)}$ Between 1981 and 2006, coronary heart disease (CHD) mortality rates in Iceland decreased by $80 \%$ in men and women aged $25-74$ years. Based on the IMPACT model, approximately $73 \%$ of the mortality decrease was attributable to risk factor reductions: cholesterol $32 \%$, smoking $22 \%$, systolic blood pressure $22 \%$, and physical inactivity $5 \%$ with adverse trends for diabetes $(-5 \%)$ and obesity $(-4 \%)$. Approximately $25 \%$ of the mortality decrease was attributable to treatment of individuals. ${ }^{(27)}$ To a large extent, the decrease in CVD mortality rates and attributable risk factors have been associated to a change in lifestyle including dietary changes such as lower intake of saturated fat, this is discussed later in this report (see Section 3.5. Improved diet and lower prevalence of heart disease). Increased disease prevalence, e.g. type 2 diabetes, is especially pronounced in population subgroups such as the elderly, immigrants and individuals with a lower educational background. In fact, almost all five Nordic countries report increasing social inequalities with lower health status and marginalisation of subgroups as a major challenge to the national public health. ${ }^{(2-5)}$

Industry reformulation and taxations are measures implemented to counter the challenges posed by the increased burden of diet-related diseases. The Keyhole symbol is another successful Nordic initiative established in Sweden in 1989 and applied to food products containing less fat, salt, sugar and more wholegrain according to recommendations in order to make healthy food choices easier within a food group. Soft drinks and sweets cannot be labeled with the symbol. In 2009, the Keyhole symbol was introduced in Denmark and Norway, and in 2013 in Iceland. Recently, the recognition of the label and its purpose was found among $80 \%$ and $98 \%$ of consumers in Sweden, Denmark and Norway and is therefore well known by the public. In Finland, the Heart symbol was initiated as a label for a better nutritional choice in its product group regarding fat (quantity and quality) and sodium, and in some product groups, also sugar and fibre content. National campaigns on wholegrain have also been implemented to increase the awareness of the potential health impact in Denmark, ${ }^{(2)}$ which is considered an important first step to increase consumption of wholegrain and dietary fibre in the future.

Changes in overall dietary patterns and especially an increased prevalence of eating away from home and increased consumption of fast foods are considered a potential nutritional challenge, especially among certain vulnerable groups.

National agricultural production is relevant to public health in terms of food production and availability. Danish farming remains focused around pig production, whereas Sweden has shifted 
to more poultry production. Norway, on the other hand, is one of the world's leading seafood producers, and during the period between 2004 and 2012, Norway doubled its salmon production. Fish consumption is considered a common Nordic trait.

\section{Review of progress in nutrition-enhancing policies and programs in the Nordic countries}

\subsection{Nutrition-enhancing policies and programs}

Over the last decades a number of nutritional policies and programs have been implemented in the Nordic countries throung the Nordic Nutrition Recommendations (NNR).

\subsubsection{The Keyhole and the Heart symbols}

The Keyhole symbol is one example of the fruitful Nordic co-operation. The symbol is a joint Nordic nutritional label used on food packages that aims to assist consumers choosing the healthier food item(s) in certain product groups in an easy way. The Keyhole symbol is based on criteria for the content of less and healthier fat, less salt and sugar, more whole grain and fiber. The symbol is voluntary for manufacturers to use. The Keyhole symbol has existed in Sweden for more than 25 years, and in 2009, a common regulation with similar criteria were publised in Sweden, Norway and Denmark. In 2013, Iceland followed.

In Finland, a similar symbol called the Heart symbol has been implemented as the nutrition label used on food packages to assist consumers choosing the healthier food item(s) in certain product groups. The Heart symbol is based on criteria for the content of dietary fibre, salt, sugar and fat (amount and type), as well as cholesterol for some food groups. The Heart symbol has been in use since 2000 , covering more than 600 products on the market today and it is well recognised by the Finnish consumers. The Finnish authorities are considering whether it would be possible to incorporate the same criteria in the existing Heart symbol as are used for the Keyhole symbol. The common goal of the Keyhole and the Heart symbols' labelling (see Table 7 for details) is to affect the food choice of Nordic citizens in a direction of healthier food choices and ultimately improved health. The symbols also encourages the food industry to produce healthier products. 
Table 7. The food product groups where the Keyhole and the Heart symbols are applied

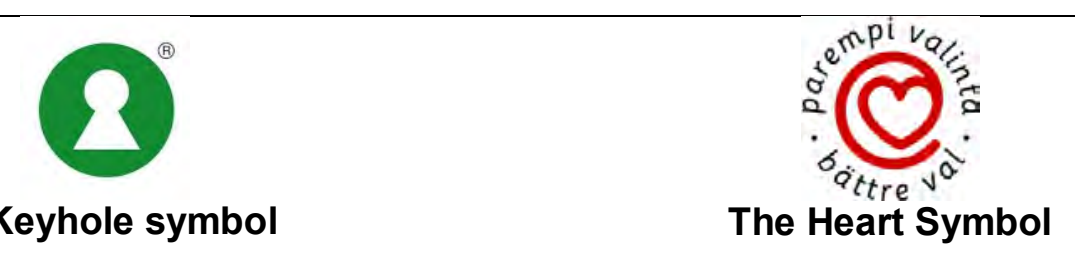

\section{The Heart Symbol}

The Keyhole symbol

$$
\text { Dairy products }
$$

Low fat spread, margarine and oils

Meat and processed meat products

Fish and shellfish

Vegetarian products

Bread, pasta, breakfast cereals, flour and whole meal

Ready meals, pies, pizza, soups, sandwiches and wraps

Potatoes and vegetables

Fruits and berries

\section{Milk and dairy products}

Oils and fats

Fish

Meat

Meat products

Bread and cereal products

Convenience foods

Spices and seasoning sauces

Vegetables, fruits and berries

\subsubsection{Increase the fruit and vegetable intake}

The intake of fruits and vegetables are lower than recommended in the Nordic countries. In light of the beneficial health effects of a higher consumption of fruit and vegetables, a policy framework aiming to increase fruit and vegetable intake was formed in the Nordic countries. The framework was presented differently in each Nordic country, often as a guideline on fruit and vegetable intake as portions or amounts per day. ${ }^{(28,29)}$

\subsubsection{Whole grain campaign}

Based on the dietary guidelines, whole grain campaigns have been set forth in the Nordic countries to emphasise the potential health benefits of diets rich in whole grain. In Denmark, Iceland and Norway, a particular whole grain label has been produced to make it easier for the consumer to recognize and choose whole-grain rich foods. A whole grain campaign in Denmark was launched through a private-public partnership in 2009 and it has served as a strong basis for industrial 
development of innovative whole grain products. The whole grain campaign has resulted in an increased public awareness of the potential health effects of whole grain and has led to a considerable increase in whole grain consumption. Furthermore, it has had great impact on the industry because it has encouraged manufacturers such as bakeries to produce a number of whole grain products.

\subsubsection{Lowering the consumption of trans fatty acids}

The adverse health effects of an intake of trans fatty acids have been known for a long time. In 2004, Denmark implemented new legislation to regulate the content of trans fatty acids in foods to a maximum of $2 \%$ of the total fat content. This regulation is mainly directed towards fats in margarines and as ingredients in certain food categories. Iceland and Norway have also implemented legislation to regulate the content of trans fatty acids in foods.

\subsubsection{The Nordic welfare state}

The similarities of the Nordic countries are sufficient to constitue a common „Nordic welfare model“. The model is based on values of equal opportunities, social solidarity and security for all and is designed to meet new challenges. Examples of areas in which the Nordic countries have special competencies are gender equality, care of the elderly, health centres and hospitals. The Nordic welfare provision is diverse and it enables the Nordic countries to learn from each other experiences, where the Nordic Council of Ministers and the Nordic Council play an important role. (30)

\subsubsection{Nordic salt project}

A common Nordic project on salt has been initiated with the aim to increase the knowledge among consumers about the potential adverse health effects of a high intake of salt and about the fact that the majority of the salt intake is derived from processed foods. The success criteria of this cooperative project include 1) an increased knowledge among consumers will increase the demand for foods with a lower salt content and 2) a reduction of the salt content of foods which traditionally have a high content of salt. During the project, each country conducts measurements among consumers on their knowledge about the potential adverse health effects of high salt intake as well as other communication activities.

\section{2 'Nordic diet' projects}

Several Nordic nutrition research projects have investigated the association between a Nordic diet and health. However, the specific scientific emphasis on local Nordic diets, sustainability and health is relatively recent. A Nordic diet is commonly defined as a diet containing native berries, 
fruits such as apples, cabbage, root vegetables, low-fat dairies, fish and other seafood, wild (and pasture-fed) land-based animals, rapeseed oil and grains such as oat, barley and rye. The Nordic Centre of Excellence Program on Food, Nutrition and Health, which is operated by the Nordic Council of Ministers, has funded three extensive projects in this field: HELGA, SYSDIET and MITOHEALTH. Furthermore, national projects, such as the OPUS project in Denmark and NORDIET in Sweden, have added vast information regarding the health effects of a Nordic diet. Networks such as the New Nordic Food Network focusing on regional food and culinary experimentation of the Nordic foods have provided added information on the benefits of the Nordic diet. Some of the projects emphasize the health effects of special Nordic food items, e.g. the HELGA project focuses on the health effects of whole grain with specific emphasis on rye, and the MITOHEALTH project places emphasis on seafood, and yet other projects investigate the health effects of the Nordic diet as a whole.

A common aim of the mentioned projects is to assess the impact of a Nordic diet which follows the NNR and the national Food Based Dietary Guidelines as part of a healthy lifestyle and evaluate the effects of food on selected health outcomes and sustainability. These projects have resulted in numerous peer-reviewed scientific papers. Further details of selected Nordic projects funded by the Nordic Centre of Excellence Program or locally are listed below.

\section{The Nordic Centre of Excellence Program on Food, Nutrition and Health}

\subsubsection{HELGA: Nordic Health - Whole grain Food}

The aim of this project was to investigate the health effects of whole grain in preventing lifestyle diseases such as cancer, cardiovascular disease, type 2 diabetes and mortality in a multicenter study including all five Nordic countries. Whole grain foods are commonly consumed in most of the Nordic countries, although in various amounts, and the effects of whole grain intake on e.g. lipid and glucose metabolism, inflammation markers, and apoptosis were investigated. ${ }^{(31)}$ The HELGA project was partly based on the epidemiological data of the Danish Cancer Society including dietary intake and end-points concerning health and disease of interest. The health effects of whole grain product consumption were therefore prospectively examined using these data, and furthermore new intervention studies were conducted. Several interventions with rye especially were conducted within the HELGA project. Some of the studies included in HELGA suggest that dietary fiber and whole grain intake are associated with lower risk of colorectal cancer. ${ }^{(32-34)}$ Furthermore, associations were found between adherence to a healthy Nordic diet and lower 
mortality rate. ${ }^{(35,36)}$ Association between intakes of whole grain and risk of type 2 diabetes is now under investigation and the results are expected in 2015.

\subsubsection{MITOHEALTH: Centre for Bioactive Food Components and Prevention of Lifestyle Diseases} The main aim of this study was to investigate which components in marine raw materials have a beneficial effect on health and could possibly diminish the risk of lifestyle diseases and to develop new functional food for the Nordic countries. ${ }^{(37)}$ It is well known that fish and other seafood is healthy and may decrease the risk of lifestyle diseases. This might be through improved metabolic process in the cells and in the mitochondria. This study was a multi-centre collaboration between Norway, Finland, Denmark and Sweden, which was divided into several work packages which consisted of animal studies, laboratory studies and clinical trials. In recent years, there have been numerous of papers published in peer-reviewed journals based on this project.

\subsubsection{SYSDIET: Systems biology in controlled dietary interventions and cohort studies}

The aim of this project was to investigate and understand the effects and system biology of healthy Nordic foods on promoting health and prevention of metabolic syndrome and other related diseases. ${ }^{(38)}$ The research within SYSDIET was organised in three working groups, concentrating on methodological issues, mechanistic studies and a joint large multi-centre human dietary intervention study. ${ }^{(38)}$ Subjects with metabolic syndrome or at risk of developing metabolic syndrome participated in a randomized controlled multi-centre study which was the main cornerstone of the SYSDIET project. The study was implemented in Denmark, Finland, Iceland and Sweden. The participants were randomized either to adhere to a Healthy Nordic Diet (formed on the basis of $4^{\text {th }}$ edition of NNR) or a Control Diet for 18-24 weeks. The intervention revealed, among other things, that dietary advice given on healthier Nordic food items improved the nutritional quality of the diet in this group of people. ${ }^{(39,40)}$ Among the advantages from consumption of a Healthy Nordic Diet was improved lipid profile and beneficial effect on low-grade inflammation. ${ }^{(40)}$ Publications based on the SYSDIET including reports on new biomarkers and health effects are now available.

\section{Other projects on Nordic diet}

\subsubsection{New Nordic Food}

The main aim of this Nordic program was to initiate a number of activities, projects and campaigns to increase communication and visibility of the New Nordic Food. With this program, the Nordic governments aim to increase knowledge and awareness of the New Nordic Food and reinforce its 
place on the global food market. ${ }^{(41)}$ This network program emphasized further development and strengthening of the New Nordic Food as a concept with communication as a key tool.

\subsubsection{NORDIET}

The aim of this study was to investigate the effects of a healthy Nordic diet on cardiovascular risk factors, with emphasis on cholesterol levels, blood pressure and insulin sensitivity. In this randomized controlled intervention study, conducted in Sweden, a comparison was made between health effects of the healthy Nordic diet and the average consumption of a reference population. The participants were mildly hyper-cholesterolaemic subjects and were randomized either to adhere to the healthy Nordic diet or the control diet for 6 weeks. The Nordic diet was based on the NNR 2004 and environmental and agricultural traditional aspects were taken into consideration. Furthermore, the Nordic diet was chosen in terms of seasonal variation and the availability of the foods. The results indicated that a healthy Nordic diet may improve blood lipid profile and insulin sensitivity and lowers blood pressure in this group of people. ${ }^{(42)}$

\subsubsection{OPUS: Optimal well-being, development and health for Danish children through a healthy New Nordic Diet}

The aim of this Danish project was to develop a palatable healthy New Nordic Diet (NND) where gastronomic potential were taken into account and the potential health effects investigated in overweight adults and healthy school children through the establishment of a multi-disciplinary research centre. Regional food items and environmental sustainability were important principles in the development of the NND. This project is only based on Danish funding and Danish conditions.

\subsection{Risk analysis approach: assessment, management and communication}

Risk analysis as a three-step process has strong roots in the Nordic countries following international standards. After identification of a problem, an assessment of the risk and benefits are made by an independent scientific body and the management done by another body/authority. Finally, communication is done separately. A good example of a well-executed risk analysis was made when a study by Ljung et al. $2011^{(43)}$ raised a concern about contaminants and minerals in foods for infants and young children. Following these study results, the Swedish National Food Agency initiated a project that assessed contaminants and minerals in infant formula and certain foods for infants and young children. A total of 92 different products on the Swedish market were analysed for the contaminants arsenic, cadmium and lead and for the essential minerals manganese, iron and copper. The results of this project were presented in an extensive report with the following three parts: ${ }^{(44)}$ 
- Part 1: Contaminants and minerals in foods for infants and young children - Analytical results, Report $1 / 2013$.

- Part 2: Contaminants and minerals in foods for infants and young children - risk and benefit assessment, Report 1/2013.

- Part 3: Contaminants and minerals in foods for infants and young children - risk and benefit management, Report 1/2013.

The assessment showed that it was mainly cereal-based, including rice, and soya-based products that had high levels of certain minerals and heavy metals and that therefore potentially could result in adverse health effects in infants and young children. These groups are considered particularly vulnerable for exposure of certain contaminants and minerals and this could pose a risk to their development. Following these results, the Swedish authorities gave advice to consumers on how to avoid high intakes. This advice was later shared with and incorporated in all other Nordic countries. ${ }^{(44)}$ Furthermore, advice, information and proposals were set forth for healthcare and medical services, control authorities in Sweden, companies, EU Commission and the European Food Safety Authority (EFSA).

The above example illustrates the close collaboration between the Nordic countries, made possible because of many similarities of dietary habits. Similarities in infrastructures make organized decision easier, and different institutions in the Nordic countries are able to collaborate by sharing and trusting - leading to an increased quality of the decisions.

\section{Nordic regional nutrition initiatives}

\subsection{Nordic Nutrition Recommendations}

For decades, the Nordic countries have been collaborating in setting recommendations for nutrient intake by publishing the NNR. ${ }^{(13)}$ The NNR are evidence-based recommendations that involve the work of scientific experts mainly from Nordic universities. The NNR have been published approximately every eight years with the first edition in 1980, and the fifth edition in 2014. In the first edition of the NNR, recommendations were presented on macronutrient composition and the consumption of dietary fibre and micronutrients. Subsequent editions thereafter (second edition, 1989, and third edition, 1996) focused on fat intake and furthermore highlighted the importance of the fat quality. In the fourth edition, physical activity was integrated. In the latest edition of the NNR, emphasis was placed on the diet as a whole, and the dietary reference values for the intake of 
individual nutrients were included as in the previous editions. In addition, an increased focus was put on the role of dietary pattern and food groups associated with the reduced risk of diet-related non-communicable diseases (NCDs) and weight maintenance. ${ }^{(14)}$ Included in the latest edition is also a chapter on environmental issues of food production and sustainability. Through the years, changes in the guidelines have been made when strong scientific evidence has evolved between editions. The most recent NNR were based on systematic literature reviews for nutrients when the amount of new data was considered sufficient to provide a basis for a strengthened scientific basis for the recommendations.

The long and fruitful Nordic collaboration has resulted in extensive progress in the nutritional field in the Nordic countries. Historically, the NNR were used as nutrient recommendations and as a basis for developing national Food Based Dietary Guidelines (FBDG) that are used as guidelines for planning diets. Denmark and Norway recently developed FBDG based on systematic literature reviews of dietary studies (cohort, other epidemiological and randomized controlled studies) and the NNR were used for quantification of dietary intake.

The common NNR and the national FBDGs support local food production, biodiversity and the cultural differences that exist within the Nordic countries. The general components of the Nordic FBDG include:

- Increasing fruit and vegetable consumption to 500-600 g/day (including $100 \mathrm{ml}$ of juice per day and excluding intake of potatoes)

- Increasing consumption of whole grain

- Increasing fish consumption to 2-3 fish meals per week

- Limiting processed and red meat consumption (<500g per week)

- Sensible consumption of milk products (2 portions per day/cheese)

- Good sources of fat (fatty fish, rapeseed oil, olive oil, avocado, nuts)

- Lowering consumption of sugar-sweetened beverages and foods with added sugar

- Reducing salt intake

- Increasing physical activity

Cod-liver oil or other D-vitamin supplements are recommended in Iceland and Norway during the winter and in other countries for specific vulnerable groups.

The NNR are intended for the general population and should ensure optimal nutrition that provides a basis for good health and furthermore reduce the risk of diet-related non-commmunicable 
diseases. It should however be kept in mind that for vulnearble groups and those with special needs, more extensive nutrition recommendations may be more appropriate.

The NNR are evidence-based recommendations and have no conflict of interest with the industry. However, the NNR place demands on the industry to produce healthier products in line with the NNR and can thus be used as an example for other countries. The NNR collaboration has led to numerous health-related research interventions, campaigns and other smaller and larger projects.

\subsection{Nordic conferences}

A series of Nordic Nutrition Conferences were initiated in 1977, and since 1980 have been held every fourth year in the various Nordic countries. The 11th Nordic Nutrition Conference will take place in Gothenburg in 2016. Along the same line, a series of Nordic Public Health Conferences have been held regularly on various pertinent issues. Both series are supported by the Nordic Council of Ministers and bring the Nordic co-operation closer at all levels.

\subsection{Regional foods and the Nordic diet}

One of the important justifications for the Nordic collaboration is that dietary habits are similar accross the Nordic countries as is the prevalence of diet-related NCDs. The Nordic experience is that smaller nations working together make a stronger impact both internally and externally. Nordforsk is an organisation under the Nordic Council of Ministers that provides funding for Nordic collaboration and is therefore an important funding instrument for scientific projects such as The Nordic Centre of Excellence. The good collaboration of the Nordic countries has resulted in numerous health interventions and campaigns that aim to improve overall health of the Nordic citizens. As an example of the strong advocacy based on the NNR, there is an increased prevalence of breastfeeding rates in most Nordic countries.

Recent studies on "Nordic diets" suggest that a diet based on locally produced food items may be related to improved cardiovascular health in the short term, improved lipid profile and insulin sensitivity, beneficial effect on low-grade inflammation and lower mortality rates. ${ }^{(39,45,46)}$ Furthermore, studies on local diets in the Nordic countries (see below) indicate that they are more sustainable, fulfil recommendations on nutrients and FBDGs, and promote health. Although further research is needed, studies suggest that by advocating a Nordic diet in the Nordic countries may contribute both to better public health and benefits to the environment. In addition, it may be easier for consumers to make changes in their diet by using the Nordic diet because people are more likely to increase the intake of commonly eaten foods than eating unfamiliar food types. 


\subsection{Environmentally sustainable diets}

Global environmental problems have been increasing during the last decades, resulting in a growing awareness in the Nordic countries of the environmental impacts of the food chain from production to consumption and the desire to diminish the carbon footprint. ${ }^{(47,48)}$ Increased awareness about the climate impact of dietary intake has also led to an increased interest in locally produced food. Health promotion and environmentally friendly diets have been described in a special Nordic context. ${ }^{(47)}$

Sustainable diets have been defined as

- diets of a population continued over a long time without damage to the environment, i.e. based on sustainable use of resources and without harmful pollution,

- diets that promote the health of the population at all ages and conditions and consider the impact of diet in a life cycle context, and

- diets that preserve biodiversity.

Food production and food consumption contribute to the total climate impact, i.e. greenhouse gas emissions (carbon footprints). Factors related to foods are estimated to be responsible for about $30 \%$ of the greenhouse gas emissions in the EU. ${ }^{(49)}$ This amount could be diminished by optimizing the choice of foods with respect to carbon dioxide $\left(\mathrm{CO}_{2}\right)$ production. Factors in the food production chain that have been found to affect the carbon footprints are the following:

- Primary production in agriculture, fishing, etc.

- Preparation, packaging, transport and storage

- Refrigeration or freezing

- Cooking, consumption and waste at household and other levels

- Origin of energy used in the production

- Food waste at all levels of the food chain

Dietary guidelines with environmental advantages include diets with reduced amounts of meat, which is one of the major contributors to global warming, ${ }^{(50)}$ and increased amounts of vegetables. Such guidelines are in line with the NNR and can also be in line with diets where waste of edible foods is reduced. Preference for foods of the season, increasing consumption of locally produced foods to avoid long-distance transport, and using less industrially prepared foods compared with 
home-cooked foods have been described as environmentally friendly. ${ }^{(51-53)}$ Table 8 shows the main emphasis of the changes in dietary pattern recommended in the NNR 2012.

Table 8. Food consumption changes to promote energy balance and health in Nordic populations.

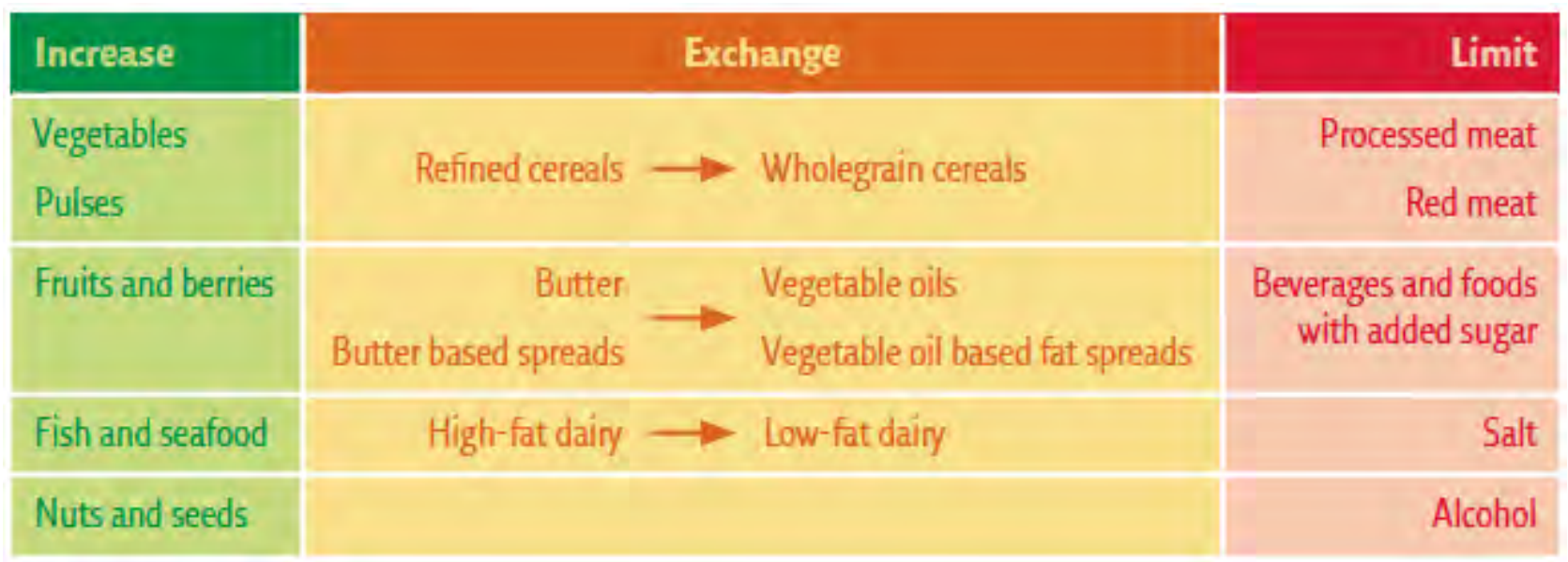

*Source: Nordic Nutrition Recommendations 2012. ${ }^{(14)}$

Estimated decreases in the carbon footprint are between 4\%-15\% when the national FBDGs are followed, and examples have estimated that it would be possible to reduce the $\mathrm{CO}_{2}$ production with a total of $23 \%$ when simple choices of foods are optimized within each food group, i.e. by choosing locally produced foods instead of foods transported far. ${ }^{(54,55)}$ More complex optimized choices within all food groups are expected to provide even further savings, but further research is needed in the area of the Nordic context. Combined with further reduction of food waste, it will have a major effect on the carbon footprint. Therefore, following the FBDGs and further selecting foods with the environment in mind will decrease the dietary carbon footprint and have a significant positive impact on the environment. In conclusion, there is evidence to complement the FBDGs with additional advice to reduce the carbon footprint from food consumption.

\subsection{Improved diet and lower prevalence of heart diseases}

Studies suggest that higher intake of vegetable, fruit, berries and whole grain are associated with reduced risk of CVD and lower levels of CVD risk factors. ${ }^{(54,56-58)}$

High consumption of saturated fat and trans fatty acids is negatively associated with cholesterol, which is one risk factor for CVD. A recent large epidemiological study in Iceland suggests that the 
decrease in cholesterol levels of the population is mainly due to dietary changes resulting in less consumption of total fat and especially less saturated and trans fatty acids over the last decades. ${ }^{(59)}$ Similarly, a community-based program in Finland, the North Karelia Project, was initated in 1972 because of the high CVD mortality rate in the country. ${ }^{(60)}$ The project showed that it is possible to influence lifestyles and reduce cardiovascular rates by reducing certain risk factors. In this project, the dietary changes over a 25 -year period resulted in about a $17 \%$ reduction in the mean serum cholesterol level at the population level. The project also convincingly showed that replacing saturated fat with unsaturated fat and polyunsaturated fat (PUFA) had a positive health impact. ${ }^{(56,61)}$ These studies therefore strongly indicate that following a diet in accordance with the NNR beneficially affect the risk factors of CVD. ${ }^{(62-64)}$ However, the frequency of type 2 diabetes is still increasing, partly due to the number of overweight and obese people.

\section{Nordic Plan of Action}

In July 2006, the Nordic Council of Ministers - the Ministers for Fisheries and Aquaculture, Agriculture, Food and Forestry and the Ministers for Health and Social Affairs - committed themselves to address the issues of an unbalanced diet, physical inactivity and overweight population and enacted policies to promote a healthier lifestyle by adopting a Nordic Plan of Action on Better Health and Quality of Life through Diet and Physical Activity. ${ }^{(65)}$

In the Nordic Plan of Action, the Nordic Council of Ministers formulated common Nordic ambitions in short-term goals and longer term visions, whereby national actions could take place in each of the Nordic countries. A common tool in the Nordic Plan of Action was the development of a common monitoring system to assess the development and the effects of different actions, and an increased sharing of knowledge, a common effort to identify best practice, and increased scientific cooperation.

\subsection{Goals and visions of the Nordic Plan of Action}

Through an interactive process between scientists, authorities, and stakeholders, the goals of the Nordic Plan of Action for 2011 and visions for 2021 were formulated into the following:

\section{Diet}

Goal 2011: The consumption of fruits and vegetables and of whole grain bread/cereals has increased, and the intake of fat, especially saturated fat and trans fatty acids, and added sugar has 
been reduced. The intake of salt has been maintained or reduced, depending on the specific national context.

Vision 2021: A major part of the population is eating according to the Nordic Nutrition Recommendations applicable. The current references for the vision are the following: At least $70 \%$ of the population above 10 years has a daily intake of fruits and vegetables of at least $500 \mathrm{~g} /$ day. The average intake of children, 4-10 years, is at least $400 \mathrm{~g} /$ day.

The average dietary intake of the population meets the NNR on fat and saturated fat plus trans fatty acids (30\% of energy (E\%) and about $10 \mathrm{E} \%$, respectively), and at least $70 \%$ meets the NNR on fat ( $E \%$ between 25 and 35$)$.

$80 \%$ or more meet the NNR on daily intake of added sugar (max. 10 E\%).

$70 \%$ or more consume fish or fish products, corresponding to a main dish twice a week.

At least $70 \%$ of the adult population has a daily intake of whole grain bread/cereals corresponding to at least half of their daily intake of bread/cereals.

The average diet of adults meets the NNR on salt.

\section{Physical activity}

Goal 2011: The current trend, where an increasing proportion of adults and children are physically inactive, has been brought to a halt and at best reversed.

Vision 2021: At least 75\% of the adult population is physically active (moderate intensity) for at least 30 minutes every day.

All children aged 1-12 years and at least $85 \%$ of children and youth aged 12-16 years are physically active (moderate intensity) for at least 1 hour every day.

\section{Overweight and obese population}

Goal 2011: The continuing increase in the proportion of the overweight and obese has been stopped and at best reversed.

Vision 2021: The number of overweight and obese adults has been reduced by at least $30 \%$ from the present level (i.e. 2006). 
The number of overweight and obese children and adolescents has been reduced by at least $50 \%$ from the present level.

\section{Social inequality in health related to diet and physical activity}

Goal 2011: Existing differences between different social groups with regard to overweight, obesity, unhealthy diet, and physical inactivity have not deepened further and at best have been reduced.

Vision 2021: The variation between different social groups on meeting the defined objectives with regard to diet, physical activity, and weight/obesity is at most $20 \%$.

\subsection{Implementation/activities}

For the implementation of the Nordic Plan of Action, several prerequisites were anticipated by the Nordic governments:

- That a large number of sectors and stakeholders should be involved at all levels of society.

- That the individual would have the responsibility for his/her own choices.

- That special attention should be paid to groups in the society that have the most difficulty in making healthy choices.

- That the Nordic governments should focus on providing the necessary support for the development of solutions at the local community level.

- That food industry, retailers, the catering industry, and the media as well as other private stakeholders take co-responsibility and participate in efforts to promote a healthier lifestyle.

- That the governments of the Nordic countries are prepared to introduce relevant legislation, also at EU and international levels, if needed.

The Nordic Plan of Action emphasises targeted actions to ensure that the following:

Children and adolescents are enabled to make healthy choices and are protected from an environment that encourages unhealthy choices through:

- cooperation with the education sector to intensify the efforts.

- a request from the Nordic EU member countries to the EU Commission to assess whether and how regulations can contribute to common school fruit schemes, and whether current school milk schemes can be revised to promote low-fat milk. 
- common efforts to limit availability of drinks with added sugar and snacks in schools and daycare institutions.

- holding the EU Commission to its ultimatum to industry on stopping all advertising and marketing of unhealthy food directed at children.

\section{Healthier choices are made easier for all through}

- labeling of foods to make it easier for the consumer to choose healthier products.

- initiatives directed at inspiring workplaces to invest in measures to promote health and promoting local initiatives to promote a healthy diet and physical activity.

The targeted actions are directed at vulnerable and risk groups to reduce inequalities in health. Particular attention is paid to pregnant women and new parents to promote and support breastfeeding.

\subsection{Nordic monitoring}

Regularly performed Nordic surveys on diet, physical activity, and overweight provide crucial information for the formulation of policies. An important element in the Nordic Plan of Action was a common Nordic monitoring of diet, physical activity, and body weight that could provide the general public and decision-makers with adequate and updated information on status and trends in the areas of diet, physical activity, and overweight. It is the ambition that data should be collected every second year in a representative sample covering gender, predefined age groups (among children and adults), and social strata. ${ }^{(66)}$

In 2007, a Nordic working group was established and described a future Nordic monitoring system on diet, physical activity and overweight consisting of three parts:

Part 1. Description of common methods for collecting representative data on diet and physical activity

Part 2. Validation of the suggested methods against reference methods

Part 3. First collection of data in all Nordic countries

\subsubsection{Part 1. Description of common methods for collecting representative data on diet and physical} activity

Taking into consideration that all Nordic countries conduct large-scale nationwide surveys that include data on diet, physical activity and anthropometry that differ considerably with respect to 
methodology, size, frequency, target groups, etc., the working group recommended the development of new specific questionnaires that would fit the purpose of the Nordic monitoring system. The requirements for such questionnaires were that they should be simple and at relatively low cost, which would be achievable by conducting a telephone interview.

The working group emphasized that the new monitoring survey could be used to evaluate the goals and visions of the Nordic Plan of Action, and suggested that the survey may be supplemented by data from other national surveys. The working group stressed that the dietary indicator questions would not be able to measure the intake of salt in the Nordic population and therefore suggested that a specific monitoring project be initiated at the Nordic level to discuss the issue of salt reduction in prepared foods and the measurements needed for following the development. In the area of social inequality, the working group proposed new goals and visions for measuring social inequality in relation to diet, physical activity and weight.

\subsubsection{Part 2. Validation of the suggested methods}

\subsubsection{Indicators of dietary intake}

The dietary indicators comprised the following 13 questions considered suitable indicators of intake in the Nordic countries of fat, saturated fat, dietary fibre and added sugar:

$>$ frequency of eating fruit

$>$ frequency of eating vegetables

$>$ amount of slices of bread eaten during the day or week

$>$ pommes frites/fried potatoes

$>$ fish and seafood

$>$ sausages as a main meal

$>$ candy and chocolate

$>$ cakes and biscuits

$>$ full fat cheese

$>$ soft drinks (carbonated/not carbonated, sugar sweetened)

$>$ soft drinks (carbonated/not carbonated, light/artificial sweetened)

$>$ fruit/vegetable juice

$>$ type of fat spread used on bread and for frying, cooking, baking

\subsubsection{Indicators of physical activity}

The indicator questions on physical activity comprised the following:

total time in a week spent on both moderate-to-vigorous intensity physical activity 
$>$ vigorous physical activity (VPA) only

questions about TV and computer time

Overall, the validation studies for dietary intake and physical activity showed that the Nordic indicator questionnaires were suitable as a simple and low-cost common method for stakeholders throughout the Nordic region.

\subsubsection{Part 3. First collection of data in all Nordic countries}

The first collection of data provided the baseline data for frequency of intake of selected foods, physical activity level, prevalence of overweight and obese population and social inequality. The baseline data were collected as telephone interviews from October to December 2011. In total, 9153 adults (participation rate $40 \%$ ); and 2479 children aged $7-12$ years (participation rate $45 \%$ ) participated.

\subsection{Results}

\subsubsection{Dietary Intake}

The median intake of fruit and vegetables among adults was similar in all countries with consumption of fruit and vegetables between 2.5 and 3.5 times a day. Also among adults, marked differences were found between countries regarding the frequency of fish intake, the frequency and type of fat spread and type and amount of bread used.

Cakes, sugar-sweetened soft drinks and, in particular, chocolate and candy were eaten regularly among adults in all countries with a median frequency of intake of 4 times a week. Sugarsweetened soft drinks were regularly consumed by $50 \%$ of the adult population in the Nordic countries with considerable differences between countries. For children, sugar-rich foods were consumed regularly in all countries with a typical frequency of intake of sugar-sweetened soft drinks among children of once a week in all five countries. A typical frequency of intake of sugarrich food was 4 times a week, equivalent to about 200-250 g/week, which is close to the maximum level of the Nordic recommendations (10E \%).

A "healthy" dietary index was developed from the above-mentioned foods and the percentage with a diet classified as "healthy" varied considerably between countries, from $9 \%$ in Sweden up to $18 \%$ in Finland and $24 \%$ in Norway. Approximately $70 \%$ of both children and adults had a medium quality diet, and more children than adults had a poor diet. Less than $1 \%$ of adults and no children had an optimal diet. A diet defined as "healthy" was found only in $2 \%$ of children in Sweden to $10 \%-12 \%$ in Denmark and Norway. 
Considering the overall dietary habits, women had healthier habits than men, especially regarding fat intake, a higher intake of fruit and vegetables, and a lower consumption of sugar-sweetened soft drinks. Likewise, participants with a higher education in both sexes had, in general, healthier dietary habits compared with participants having a basic education. The more highly educated had a higher dietary index score, i.e. they chose oils for cooking, healthy spread or no spread on bread, vegetables and fruits more frequently and sugar-sweetened soft drinks less often, when compared with participants having a basic and no further formal education.

\subsubsection{Physical activity}

Physical activity differed considerably between countries with Finland and Sweden representing the countries with the most physically active adult participants and with about $70 \%$ fulfilling both the minimum recommendation (a 30 minutes of moderate physical activity daily), and the full recommendation (which also includes a recommendation of vigorous physical activity). Men and women did not differ significantly with respect to physical activity but more men than women tended to be inactive. Furthermore, inactivity increased and the likelihood of fulfilling the full recommendation for physical activity decreased with increasing age. In general, fewer with a higher education were inactive and more met the minimum recommendation.

Sweden and Iceland spent less time in front of a screen (TV, computer, etc.) with a median of 2.5 hours/day compared with 3.0 hours/day in the other 3 countries. In general women spent less time than men in front of a screen and the youngest age group, the group with basic education and singles had more than 4 hours screen time a day. Participants living in the countryside spent less than 4 hours a day in front of a screen, compared with participants living in a capital who had more than 4 hours screen time a day.

Among children, Finland and Iceland had the most active participants and the highest percentage fulfilling the recommendation of at least 1 hour moderate activity daily (52\% and $56 \%$, respectively). In Sweden, only $28 \%$ fulfilled the recommendation. In general, more boys than girls fulfilled the recommendation for physical activity. Overall, children in this survey spent 2-3 hours a day in front of a screen, which is slightly less than adults. Likewise for adults, more boys than girls spent more than 4 hours on screen time.

\subsubsection{Overweight and obese population}

Iceland had the highest percentage of overweight (approx. 39\%) and obese participants (approx. $18 \%$ ). Denmark, Sweden and Norway had a comparable number of overweight and obese popluation, $43 \%-45 \%$. BMI was higher among men compared with women, and it increased with aged and tended to be higher in participants with a basic but no further education. Compared with 
the urban areas, more participants living in rural areas were overweight and obese. All data were self-reported.

The number of children aged 7-12 years that identified as overweight or obese was at the same level in all 5 countries; $9 \%-15 \%$ overweight and $2 \%-4 \%$ obese.

\subsubsection{Conclusions from the first collection of data}

Overall, the baseline data in the first round of data collection in the Nordic Plan of Action comprised more than 11.500 participants in the Nordic regions and provided a valuable baseline for the status on diet, physical activity and weight.

The collection of baseline data in the study gives an overall status for dietary intake indicators, indicators for physical activity, sedentary time and weight and shows that in spite of similarities there were also national differences in dietary intake of key food groups, in physical activity patterns, and in the prevalence of overweight and obese population. The baseline data provides a basis for comparison between the Nordic countries and with the goals and visions for the Nordic Plan of Action. The results confirm that the overall status of dietary indicators could still certainly be improved, physical activity increased, sedentary time decreased and the prevalence of overweight and obese population is too high.

The second round of data will be collected in the autumn 2014.

\subsection{Concluding remark}

The Nordic Plan of Action emphasizes efforts in which Nordic co-operation through establishment of a common monitoring program enables the Nordic countries to make a continuous assessment of achievements and create further synergy and added value to common initiatives. The task of setting up a monitoring program with valid indicators has been successfully accomplished and the first monitoring results have resulted in both clear similarities and differences in dietary habits, physical activity patterns, and prevalence of overweight and obesity across the countries.

The Plan of Action thus comprises a common Nordic contribution to the international challenges on better health and quality of life, especially with regard to prevention of overweight and obesity and promoting a healthy lifestyle. The continuous monitoring will be important for following the present trends and for other initiatives to be taken. 
UNIVERSITY OF ICELAND SCHOOL OF HEALTH SCIENCES

\section{Evaluation and future challenges}

The positive trend of the Nordic collaboration can be seen in the long-running development of the NNR and shared scientific conferences and networks, which have contributed to local country dietary guidelines. The first local and later Nordic development of signals to guide the Nordic populations, i.e. the Keyhole and Heart symbols, have most likely facilitated the Nordic populations' adherence to this development. During the last 20 years, the life expectancy has increased in all the Nordic countries and the mortality rate of coronary heart disease and the prevalence of CVD have declined. To some extent these signs of improved health have been associated with better lifestyle including healthier diet. Positive trends of the dietary intake in the Nordic countries include increased intake of fruit and vegetables, and decreased intake of salt, saturated fat and sugar. However, the increased prevalence of type 2 diabetes and cancer, as well as of prevalence of overweight and obese people in the Nordic countries is alarming. Therefore tools are still needed to slow down the process and change its direction to achieve the long-term visions of the Nordic Plan of Action. A contribution to improved health is the new NNR approach on the whole diet, sustainability and physical activity as well as the relatively recent healthy Nordic diet projects which all encourage the intake of e.g. berries, whole grain and fish. The results of these projects have provided scientific evidence of improved health measures when the population adheres to the healthy Nordic diet. The Nordic Action Plan has considerably added to the tool box for improved diet, health and the possibility of measurements to follow the trends.

\subsection{General remarks on the Nordic co-operation}

The Nordic co-operation builds on common cultural values and common approaches in creating joint Nordic solutions to shared problems and strengthening regional initiatives in the area of food, nutrition, and health.

The Nordic Plan of Action on better health and quality of life through diet and physical activity is considered a very important step towards the overall goal of developing governmental strategies and policies for promotion of healthy diets and physical activity and the prevention of overweight and obesity. By taking advantage of the regional cultural practices and common approaches, the Nordic countries have initiated a unique common set of measures, including tools for benchmarking of the short-term goals and longer term visions in the area.

National initiatives have created joint Nordic solutions to shared problems. The Keyhole/Heart symbols to increase awareness of healthy food choices have been developed through sharing of experiences and best practices. Several cases on public-private partnerships have also proved 
fruitful at the Nordic level and underpinned the potential for such partnerships to bring in action and improvements.

The Nordic co-operation in the nutrition area has a long history in setting the Nordic Nutrition Recommendations. In recent years, this scientific co-operation has been reinforced through several research themes and has contributed to an increased awareness of the qualities and potentials of 'Nordic' diets.

\subsection{Future challenges in the Nordic co-operation}

Some of the challenges to be addressed in the future Nordic co-operation in the nutrition area are the following:

- The regional establishment of a common set of NNR / dietary reference values.

- Continuous monitoring of the diet, physical activity and weight in all the Nordic countries.

- Common research in effective strategies to meet future challenges of combating NCDs in the general population and vulnerable groups.

- Development of strategies to improve the nutritional impact of an increasing tendency of eating out/away from home with special focus on school meals, meals for elderly homes and for catering in general.

- Continually identifying best practices to improve nutritional intake, status and health.

- Identifying best practices in the reduction of salt intake.

- Common development and use of nutrient profiles.

- Inclusion of environmental and sustainability issues in the nutrition area.

- Combining nutrition advice and sustainable production.

- Inclusion of food waste issues.

- Overcome social inequality to ensure better public health in all groups of people.

\subsection{Future co-operation in the Nordic region}

The future co-operation in the Nordic region will continue the long tradition of working together on common challenges. Suggestions for future co-operation include the following:

- The co-operation on the updating and development of NNR will be ensured as a continuous work process with involvement of Nordic researchers.

- The common monitoring developed as part of the Nordic Plan of Action scheme will be ensured with continuous funding and even further developed to provide a strong tool for identifying trends in the development of dietary intake, physical activity and overweight/obesity.

- Development of common measures of food and nutrient related risk factors for public health issues in the Nordic countries. ${ }^{(67)}$ 
- The co-operation of the further development of dietary assessment methodology and analyses for the national dietary surveys will be ensured to meet the common dietary challenges with a more diversified food landscape.

- A further development of the co-operation on food composition tables will be supported.

- The criteria and the health impact of the labelling with the Keyhole and Heart symbols should be reviewed regularly to ensure both nutritional value and timeliness.

- The development of evidence-based common best practicies of actions in relation to dietary patterns in the Nordic region, comprising, i.e. fast food, salt, and sugar issues.

- Development of common management strategies in combatting the vitamin $D$ issues in the Nordic countries. ${ }^{(67)}$

- More emphasis should be placed on developing and exchanging best practices in the public health area ${ }^{(68)}$, including nutritional intake, status and health.

- Development of joint research infrastructures in relation to dietary intake and physical activity and their determinants and in relation to health status and their biomarkers.

- Continuing emphasis should be placed on biomonotoring and increased collaboration regarding biobanks.

- Dietary sustainability, including biodiversity, should be considered in the development of common dietary guidelines. 


\section{References}

1. FAO and WHO. (1992). International conference on nutrition: major issues for nutrition. Food and Agriculture Organization of the United Nations and World Health Organization.

2. Country Nutrition Papers from Food and Agriculture sectors prepared for ICN+21: Denmark.

3. Country Nutrition Papers from Food and Agriculture sectors prepared for ICN+21: Norway.

4. Country Nutrition Papers from Food and Agriculture sectors prepared for ICN+21: Sweden.

5. Country Nutrition Papers from Food and Agriculture sectors prepared for ICN+21: Finland

6. WHO (2012). Population-based approaches to childhood obesity prevention. World Health Organization.

7. OECD (2013). Health at a Glance 2013.

8. WHO country profiles on nutrition, physical activity and obesity in the 53 WHO European Region Member States. Available at

http://www.euro.who.int/en/publications/abstracts/country-profiles-on-nutrition,-physicalactivity-and-obesity-in-the-53-who-european-region-member-states.-methodology-andsummary-2013. Accessed $7^{\text {th }}$ September, 2014.

9. Statistics Iceland. Available at

http://www.hagstofa.is/?PagelD=2593\&src=https://rannsokn.hagstofa.is/pxis/Dialog/varval.a sp?ma=MAN02009\%26ti=Mannfj\%F6ldi+eftir+sveitarf\%E9I\%F6gum+1\%2E+desember+19 90\%2D2004+\%2D+Endanlegar+\%26path=../Database/mannfjoldi/sveit_eldra/\%26lang=3\% 26units $=$ fj\%F6ldi and

http://www.hagstofa.is/temp/Dialog/varval.asp?ma=MAN05401\&ti=Me\%F0al\%E6vilengd+o g+eftirlifendatala+1971-

2008++++++\&path=../Database/mannfjoldi/Danir/\&lang=3\&units=Fj\%C3\%B6ldi\%20\%C3\% A1ra\%20/\%20Fj\%C3\%B6Idi. Accessed $21^{\text {st }}$ August, 2014.

10. Directorate general of Health, Iceland. Available at http://www.landlaeknir.is/servlet/file/store93/item20002/Of\%C3\%BEyngd\%20Offita\%202-42013\%20\%282\%29.pdf. Accessed 24 ${ }^{\text {th }}$ August, 2014.

11. Thorisdottir B, Gunnarsdottir I, Thorisdottir AV, Palsson GI, Halldorsson TI, Thorsdottir I. Nutrient intake in infancy and body mass index at six years in two population-based cohorts recruited before and after revision of infant dietary recommendations. Ann Nutr Metab. 2013;63(1-2):145-51.

12. Nordic Council of Ministers. (2012). A better life through diet and physical activity in the Nordic countries - how far have we come? Nordic co-operation, Copenhagen, Denmark.

13. Nordic Nutrition Recommendations 2004: integrating nutrition and physical activity. 4th ed. Nord 2004:13,2004, Copenhagen: Nordic Council of Ministers.

14. Nordic Nutrition Recommendations 2012: integrating nutrition and physical activity. 5th ed. Nord 2014:002, Copenhagen: Nordic Council of Ministers.

15. What do Icelanders eat? Research on the Food Habits of Icelanders 2010-2011. Main results. Published by the Directorate of Health, Icelandic Food and Veterinary Agency, Unit for Nutrition Research 2011.

16. WHO (2009). Infant and young child feeding: model chapters for textbooks for medical students and allied health professionals. World Health Organization, France.

17. Thorisdottir AV, Thorsdottir I, Palsson GI. Nutrition and iron status of 1-year olds following a revision in infant dietary recommendations. Anemia. 2011:986303.

18. Sigbjörnsdóttir HB, Gunnarsdóttir BE. Brjóstagjöf ungbarna. Fréttabréf landlæknis um heilbrigðisupplýsingar. (Breastfeeding in infancy. Newsletter from Directorate of Health on Health Statistics) [In Icelandic] 2012;6(3):1. 
19. WHO (2013). Country profiles on nutrition, physical activity and obesity in the 53 WHO European Region Member States. The WHO Regional Office for Europe, Copenhagen, Denmark.

20. Børnedatabasen [The Danish Database on Children]. Statens Serum Institut http://www.ssi.dk/Sundhedsdataogit/Registre\%20og\%20kliniske\%20databaser/De\%20natio nale\%20sundhedsregistre/Graviditet\%20fodsler\%20born/Bornedatabasen.aspx.[In Danish].

21. Uusitalo L, Nyberg H, Pelkonen M, Sarlio-Lähteenkorva S, Hakulinen-Viitanen T, Virtanen S, editors. Imeväisikäisten ruokinta Suomessa vuonna 2010 (Infant feeding in Finland in 2010) [In Finnish, short summary in Swedish]; Helsinki: Juvenes Print; 2012.

22. Øverby NC, Kristiansen AL, Andersen LF, Lande B. Oslo: Directorate of Health; 2009. Spedkost 12 måneder. (Norwegian national dietary survey among infants at 12 months) [In Norwegian].

23. Øverby NC, Kristiansen AL, Andersen LF, Lande B. Oslo: Directorate of Health; 2008. Spedkost 6 måneder. (Norwegian national dietary survey among infants at 6 months) [In Norwegian]

24. Official Statistics of Sweden. Statistics - Health and Medical Care. Amning och föräldrars rökvanor - Barn födda 2010 [Breast-feeding and smoking habits among parents of infants born in 2010. 2012. Summary available in English]. Available at http://www.socialstyrelsen.se/Lists/Artikelkatalog/Attachments/18809/2012-8-13.pdf. Accessed $28^{\text {th }}$ August, 2014.

25. Steingrimsdottir L, Thorgeirsdottir $\mathrm{H}$, Aegisdottir S. Research on the food habits of Icelanders 1990. 1. Main results. The Icelandic Nutrition Council (Manneldisráð Íslands). Reykjavík, 1991

26. Rasmussen LB et al. (2012). Nordic monitoring of diet, physical activity and overweight: first collection of data in all Nordic countries 2011. Nordic Co-operation, Denmark.

27. Aspelund T, Gudnason V, Magnusdottir BT, Andersen K, Sigurdsson G, Thorsson B, Steingrimsdottir L, Critchley J, Bennett K, O'Flaherty M, Capewell S. Analysing the large decline in coronary heart disease mortality in the Icelandic population aged 25-74 between the years 1981 and 2006. PLoS One. 2010;5(11):e13957.

28. Pro greens - Promotion of vegetable and fruit consumption among school children in Europe. Available at http://www.progreens.org/ Accessed $8^{\text {th }}$ August, 2014.

29. Pro children - Promoting and Sustaining Health through Increased Vegetable and Fruit Consumption among European Schoolchildren. Available at http://www.prochildren.org/ Accessed August $10^{\text {th }}, 2014$.

30. Nordic cooperation. Available at http://www.norden.org/en/about-nordic-co-operation/areasof-co-operation/the-nordic-welfare-model/about-the-nordic-welfare-model. Accessed $30^{\text {th }}$ October, 2014.

31. Helga, Nordic health - whole grain food. Available at http://www.cancer.dk/helga. Accessed $9^{\text {th }}$ August ,2014.

32. Egeberg R, Olsen A, Loft S, Christensen J, Johnsen NF, Overvad K, Tjonneland A. Intake of wholegrain products and risk of colorectal cancers in the Diet, Cancer and Health cohort study. Br J Cancer 2010;103:730-734.

33. Hansen L, Skeie G, Landberg R, Lund E, Palmqvist R, Johansson I, Dragsted LO, Egeberg R, Johnsen NF, Christensen J, Overvad K, Tjonneland A, Olsen A. Intake of dietary fiber, especially from cereal foods, is associated with lower incidence of colon cancer in the HELGA cohort. Int J Cancer 2012;131:469-478.

34. Kyro C, Skeie G, Loft S, Landberg R, Christensen J, Lund E, Nilsson LM, Palmqvist R, Tjonneland A, Olsen A. Intake of whole grains from different cereal and food sources and incidence of colorectal cancer in the Scandinavian HELGA cohort. Cancer Causes Control 2013;24:1363-1374. 
35. Kyro C, Skeie G, Loft S, Overvad K, Christensen J, Tjonneland A, Olsen A. Adherence to a healthy Nordic food index is associated with a lower incidence of colorectal cancer in women: The Diet, Cancer and Health cohort study. Br J Nutr 2013;109:920-927

36. Olsen A, Egeberg R, Halkjaer J, Christensen J, Overvad K, Tjonneland A. Healthy aspects of the Nordic diet are related to lower total mortality. J Nutr 2011;141:639-644

37. MitoHealth Centre for Bioactive Food Components and Prevention of Lifestyle Diseases. Available at http://www.mitohealth.org/. Accessed $10^{\text {th }}$ August, 2014.

38. Sysdiet, Systems biology in controlled dietary interventions and cohort studies. Available at http://www.sysdiet.fi/fi/sysdiet/. Accessed 12 ${ }^{\text {th }}$ August, 2014.

39. Jonsdottir, S.E., Brader, L., Gunnarsdottir, I., Magnusdottir O.K., Schwab, U., Kolehmainen, M., Riserus, U., Herzig, K.H., Cloetens, L., Helgegren, H., Johansson- Persson, A., Hukkanen, J., Poutanen, K., Uusitupa, M., Hermansen, K., Thorsdottir, I. Adherence to the Nordic Nutrition Recommendations in a Nordic population with metabolic syndrome: high salt consumption and low dietary fibre intake (The SYSDIET study). Food Nutr Res, 2013. 57.

40. Uusitupa M et al. Effects of an isocaloric healthy Nordic diet on insulin sensitivity, lipid profile and inflammation markers in metabolic syndrome -- a randomized study (SYSDIET). J Intern Med. 2013;274(1):52-66.

41. New Nordic Food. Available at http://newnordicfood.org/ Accessed $9^{\text {th }}$ of August, 2014.

42. Adamsson V, Reumark A, Fredriksson IB, Hammarström E, Vessby B, Johansson G, Risérus U. Effects of a healthy Nordic diet on cardiovascular risk factors in hypercholesterolaemic subjects: a randomized controlled trial (NORDIET). J Intern Med. 2011;269(2):150-9.

43. Ljung K, Palm B, Grandér M, Vahter M. High Concentrations of essential and toxic elements in infant formula and infant foods - A Matter of Concern. Food Chemistry 2011;127: 943-951.

44. Contaminants and minerals in foods for infants and young children. Part 3: Risk- and benefit management. R Bjerselius, E Halldin Ankarberg, A Jansson, I Lindeberg, J Sanner Färnstrand , C Wanhainen. 2013, Sweden: Livsmedelsverket, National Food Agency.

45. Adamsson V, Reumark A, Fredriksson IB, Hammarstrom E, Vessby B, Johansson G, Riserus $U$. Effects of a healthy Nordic diet on cardiovascular risk factors in hypercholesterolaemic subjects: a randomized controlled trial (NORDIET). J Intern Med 2011; 269(2):150-9.

46. Olsen A, Egeberg R, Halkjaer J, Christensen J, Overvad K, Tjonneland A. Healthy aspects of the Nordic diet are related to lower total mortality. J Nutr 2011;141(4):639-44.

47. Bere E, Brug J. Towards health-promoting and environmentally friendly regional diets - a Nordic example. Public Health Nutr 2009;12(1):91-6.

48. Hughes R. In this issue. Public health nutrition research. Public Health Nutr 2009;12(1):2.

49. Assoc. Engineering 2009 Copenhagen; EU JRC Inst Prospective Technological Studies 2009 Environmental impacts of diet change in the EU Luxembourg.

50. Joyce A, Dixon S, Comfort J, Hallett J. Reducing the environmental impact of dietary choice: perspectives from a behavioural and social change approach. J Environ Public Health 2012: 978672.

51. Health Council of the Netherlands 2011. Guidelines for a healthy diet: the ecological perspective. The Hague; Livsmedelverket 2008. På väg mot miljöanpassade kostråd. Vetenskapeligt underlag inför miljökonsekvensanalysen af Livsmedelsverkets kostråd. Uppsala, Sweden; Mogensen L et al 2009. Institut for Jordbrugsproduktion og Miljø og Institut for Fødevarekvalitet.

52. Aarhus Universitet:Baggrundsnotat til Fødevareministeriet: Fødevarers klimaaftryk, sammenhænge mellem kostpyramiden og klimapyramiden, samt opfang og effekt af 
fødevarespild. Notat til Fødevareministeriet vedrørende: Beregning af klimaaftryk for middagsretter til klimakogebog.

53. Saxe H. The New Nordic Diet is an effective tool in environmental protection: it reduces the associated socioeconomic cost of diets. Am J Clin Nutr 2014;99:1117-25.

54. Saxe $\mathrm{H}$ et al 2013. The global warming potential of two healthy Nordic diets compared the average Danish diet. Climatic Change, 116(2), pp. 249-262.

55. Thorsen AV, Mogensen L, Jørgensen MS, Trolle E (2012) Klimaorienterede kostråd (Climate friendly dietary guidelines). Report. National Food Institute, Technical University of Denmark, Soeborg.

56. Nasjonalt råd for ernaering. Kostråd for å fremme folkehelsen og forebygge kroniske sykdommer Metodologi og vitenskapelig kunnskapsgrunnlag. Oslo, Norway: Helsedirektoratet, Avdelningen for nasjonalt folkhelsearbeid 2011.

57. Hallund J, Dragsted L, Halkjær J, Madsen C, Ovesen L, Højgaard Rasmussen H, et al. Frugt, grøntsager og sundhed Opdatering af vidensgrundlaget for mængdeanbefalingen 2002-2006. Søborg: Fødevareinstituttet DTU, Avdelningen for Ernaering 2007.

58. Mejborn H, Biltoft-Jensen A, Trolle E, Tetens I. FULDKORN Definition og vidensgrundlag for anbefaling af fuldkornsindtag i Danmark. Søborg: DTU Fødevareinstituttet, Avdelningen for Ernaering 2008.

59. Thorsson B, Steingrimsdottir L, Halldorsdottir S, Andersen K, Sigurdsson G, Aspelund T, Gudnason V. Changes in total cholesterol levels in Western societies are not related to statin, but rather dietary factors: the example of the Icelandic population. Eur Heart $\mathrm{J}$ 2013;34(24):1778-82.

60. North Karelia Project. Available at http://www.who.int/chp/media/en/north_karelia_successful_ncd_prevention.pdf. Accessed $29^{\text {th }}$ August, 2014.

61. Tetens I, Andersen L, Astrup A, Holmboe Gondolf U, Hermansen K, Jakobsen M, et al. Evidensgrundlaget for danske råd om kost og fysisk aktivitet.: Report for DTU Fødevareinstituttet, Avdelningen for Ernaering (Søborg) 2013.

62. Sandström B, Marckmann P, Bindslev N. An eight-month controlled study of a low-fat highfibre diet: effects on blood lipids and blood pressure in healthy young subjects. Eur $\mathrm{J}$ Clin Nutr 1992;46(2):95-10.

63. Raben A, Jensen N, Marckmann P, Sandström B, Astrup A. Spontaneous weight loss during 11 weeks' ad libitum intake of a low fat/high fiber diet in young, normal weight subjects. Int J Obes Relat Metab Disord 1995;19(12):916-23.

64. Marckmann P, Sandström B, Jespersen J. Favorable long-term effect of a low-fat/high-fiber diet on human blood coagulation and fibrinolysis. Arterioscler Thromb 1993;13(4):505-11.

65. Nordic Plan of Action on better health and quality of life through diet and physical activity. Available at http://archive.oxha.org/knowledge/publications/nordic-action-plan-july-2006.pdf Accessed $6^{\text {th }}$ August, 2014.

66. Rasmussen LB, Andersen LF, Borodulin K, Enghardt Barbieri H, Fagt S, Matthiessen J, Sveinsson T, Thorgeirsdottir $\mathrm{H}$ and Trolle E (2012). Nordic monitoring of diet,physical activity and overweight. Available at http://norden.divaportal.org/smash/get/diva2:701468/FULLTEXT01.pdf. Accessed $8^{\text {th }}$ October, 2014.

67. Lim et al. A comparative risk assessment of burden of disease and unjury attributable to 67 risk factors and risk factor clusters In 21 regions, 1990-2010: a systematic analysis for the Global Burden of Disease Study 2010, Lancet 2012: 380: 2224-60.

68. Bo Könberg (2014). The Future Nordic Co-operation on Health. Nordic Council of Ministers. Available at www.norden.org/en/publications. Accessed $29^{\text {th }}$ September, 2014. 